University of Nebraska - Lincoln

DigitalCommons@University of Nebraska - Lincoln

Drought Mitigation Center Faculty Publications Drought -- National Drought Mitigation Center

7-2015

Facilitating the Use of Drought Early Warning Information through Interactions with Agricultural Stakeholders

Jason A. Otkin

Mark Shafer

Mark Svoboda

Brian Wardlow

Martha C. Anderson

See next page for additional authors

Follow this and additional works at: https://digitalcommons.unl.edu/droughtfacpub

Digitart of the Climate Commons, Environmental Indicators and Impact Assessment Commons,

Epmmpnental Monitoring Commons, Hydrology Commons, Other Earth Sciences Commons, and the

Wettererkesource Management Commons

Logo

This Article is brought to you for free and open access by the Drought -- National Drought Mitigation Center at DigitalCommons@University of Nebraska - Lincoln. It has been accepted for inclusion in Drought Mitigation Center Faculty Publications by an authorized administrator of DigitalCommons@University of Nebraska - Lincoln. 


\section{Authors}

Jason A. Otkin, Mark Shafer, Mark Svoboda, Brian Wardlow, Martha C. Anderson, Christopher Hain, and Jeffrey Basara 


\title{
Facilitating the Use of Drought Early Warning Information through Interactions with Agricultural Stakeholders
}

\author{
by Jason A. Otkin, Mark Shafer, Mark Svoboda, Brian Wardlow, Martha C. Anderson, \\ Christopher Hain, and Jeffrey Basara
}

E xtreme drought events across the United States in recent years have led to large societal impacts and contributed to lower agricultural productivity in major farming and ranching areas of the country. The total cost associated with these events has been high, with the 2012 drought alone costing more than $\$ 35$ billion, making it one of the most expensive natural disasters in U.S. history. Because droughts impact more people than any other type of natural disaster, robust drought early warning systems that effectively characterize and disseminate information to vulnerable stakeholders are necessary to assist drought mitigation and climate adaptation efforts. A prime example is the National Integrated Drought Information System (NIDIS), which has a defined goal of creating a drought early warning system that provides probabilistic forecasts with sufficient spatial

AFFILIATIONS: OTKIN-Cooperative Institute for Meteorological Satellite Studies, University of Wisconsin-Madison, Madison, Wisconsin; SHAFER—Oklahoma Climatological Survey, University of Oklahoma, Norman, Oklahoma; SvOBODA-National Drought Mitigation Center, University of Nebraska-Lincoln, Lincoln, Nebraska; WARDLOW-National Drought Mitigation Center, and Center for Advanced Land Management Information Technologies (CALMIT), University of Nebraska—Lincoln, Lincoln, Nebraska; ANDERSON-Agricultural Research Services, United States Department of Agriculture, Hydrology and Remote Sensing Laboratory, Beltsville, Maryland; HaIN-Earth System Interdisciplinary Center, University of Maryland-College Park, College Park, Maryland; BASARA-Oklahoma Climatological Survey, and School of Meteorology, University of Oklahoma, Norman, Oklahoma

CORRESPONDING AUTHOR: Jason A. Otkin, 1225 W. Dayton St., Madison, WI 53706

E-mail: jason.otkin@ssec.wisc.edu

DOI:I0.II75/BAMS-D-14-00219.I

(C)2015 American Meteorological Society and temporal resolutions for users to make informed management decisions.

Drought is often thought of as being a slowly developing climate phenomenon that takes many months or even years to reach its full intensity; however, recent events across the central United States have shown that drought development can occur very rapidly if extreme weather anomalies remain over the same area for periods as short as a few weeks. Low rainfall combined with anomalously high temperatures, strong winds, and sunny skies can act together to quickly deplete root zone soil moisture, thereby leading to the rapid emergence of agricultural drought conditions. It has become common in recent years to refer to these rapid-onset drought events as "flash droughts" to better distinguish them from other droughts that develop more slowly. Flash droughts can have an impact on agriculture that is more severe than that associated with a slower developing but longer lasting drought simply because there is less time to prepare for the adverse effects of drought when it develops so quickly. For example, according to the U.S. Drought Monitor (USDM), many locations across the central United States during the 2011 and 2012 flash droughts experienced up to a three-category increase in drought severity in only one month, meaning that areas that were drought free at the beginning of the month were characterized by severe to extreme drought conditions by the end of the month. Drought early warning during these rapidly evolving situations, however, is difficult to obtain using existing drought forecasting products that tend to focus on seasonal time scales and may only be updated on a monthly basis. Early warning systems could be significantly enhanced by integrating new datasets that provide information over subseasonal time scales ( $<3$ months) with frequent update cycles (weekly), both of which are necessary for early detection of rapidly evolving flash drought events. 
Recent research has shown that drought early warning signals can be identified using drought indicators such as the Evaporative Stress Index (ESI), which depicts standardized anomalies in evapotranspiration (ET; the combination of evaporation from bare soil and transpiration from vegetation) using land surface temperature data retrieved from satellite thermal infrared imagery and a land surface energy balance model. Early warning is possible because, in the absence of other stressors such as disease, the amount of water vapor transpired by vegetation will be dependent on the root zone soil moisture content, with below-average ET during the growing season indicating that plants are experiencing moisture stress. Drought early warning signals often occur in the ESI several weeks prior to their appearance in other drought indices because stress-induced impacts on transpiration and canopy temperature often precede a visible decrease in green vegetation cover. Furthermore, energy balance methods for retrieving ET explicitly capture the major drivers of flash drought development, including increased evaporative demand and stronger winds-each of which enhance evaporative loss of soil moisture to the atmosphere.

To better understand how this drought early warning information could be used to mitigate drought risk, focus group meetings were convened with stakeholders in two NIDIS pilot regions in the central United States. This article presents results from these meetings and discusses how they facilitated valuable interactions that serve as an example of how drought early warning information can be more effectively disseminated.

FOCUS GROUP MEETINGS. Two focus group meetings were convened in August 2014 with stakeholders in the NIDIS Southern Plains and Missouri River basin regional drought early warning system pilot regions that were impacted by severe droughts in recent years. The first meeting was held in Norman, Oklahoma, and the second convened two days later in Lincoln, Nebraska. All attendees were invited based on their prior interest in drought mitigation, with a total of 30 people from diverse backgrounds attending the meetings. Overall, $70 \%$ of the attendees were from university, federal, and nonprofit scientific organizations, $20 \%$ were from state and local government, and $10 \%$ were full-time farmers or ranchers, with most either directly or indirectly involved in agriculture.

Each focus group meeting included an interactive discussion on the characteristics of flash drought events and their societal impacts, along with several presentations introducing the attendees to the ESI and associated drought monitoring products. These include ESI "change anomalies" that show how rapidly the ESI is changing with time compared to climatology, and the Rapid Change Index (RCI) depicting the accumulated moisture stress change occurring over longer time periods. The RCI and ESI change anomalies can be used to identify regions with unusually rapid increases in moisture stress, which prior work has shown often precede periods of rapid drought development as depicted by the USDM. Experimental drought intensification forecasts derived from the RCI were also shown. These forecasts provide a probabilistic likelihood of drought intensification occurring over a 2-8-week time period based on the value of the RCI. All datasets are routinely computed at $4-\mathrm{km}$ spatial resolution across the contiguous United States, with weekly updates during the growing season that promote early warning of flash drought development at regional-to-local scales. The attendees were asked to assess the usefulness of these datasets for drought planning and mitigation efforts through group discussions, analysis of recent flash drought events, and a written questionnaire provided at the end of each meeting.

\section{FLASH DROUGHT CHARACTERISTICS AND}

IMPACTS. As discussed earlier, flash droughts are more likely to develop when dry weather, hot temperatures, strong winds, and sunny skies occur together. Many attendees noted that these conditions often lead to the rapid depletion of stock water ponds, greater heat stress on livestock, and the rapid deterioration of crop and rangeland health. It was also noted that differences in local farming practices strongly influence the vulnerability of an individual farm to extreme weather anomalies and to flash drought development. For example, soil management practices such as planting cover crops and using conservation tillage can impact drought severity at the farm scale through changes in evaporation and water transfer within the soil column. Different soil characteristics such as soil type, water-holding capacity, and infiltration rate also influence local resiliency to flash drought. At the regional scale, differences in vegetation type and farming practices may also impact the timing and severity of drought. Across the Southern Plains, widespread tillage after the winter wheat harvest in the spring produces large areas of bare soil that absorb more solar radiation than surrounding vegetated areas. This may lead to hotter air and soil temperatures that intensify local drought conditions and influence surrounding 
areas through changes in boundary layer structure and mesoscale circulations. It was also suggested that early spring green-up could lead to earlier drought onset during the summer because the vegetation will begin to deplete soil moisture earlier than normal, thereby leaving it more susceptible to drought if spring rains are less than normal.

\section{ASSESSMENT OF THE ESI DATASETS AS} DROUGHT EARLY WARNING TOOLS. During

each meeting, the attendees were shown results from several drought case studies depicting the evolution of the ESI, ESI change anomalies, RCI, and drought intensification probabilistic forecasts. They were then asked to assess their drought early warning utility through comparison with the USDM, Palmer Drought Severity Index, Palmer Z-Index, Standardized Precipitation Index (SPI), and soil moisture anomalies from the North American Land Data Assimilation System. These datasets were presented either as domain maps (examples shown in Fig. 1) or as a visualization tool referred to as a "plume diagram" (example shown in Fig. 2) that was developed to display time sequences of multiple datasets on a single image. These diagrams allow the user to quickly evaluate the evolution of multiple datasets over a specific region-such as an individual county-without the need to examine potentially dozens of domain maps.

Overall, most attendees had a favorable opinion of the ESI, RCI, and drought intensification probabilistic forecasts, with positive ratings of $89 \%, 68 \%$, and $89 \%$, respectively. The attendees generally preferred to use the ESI and RCI variables in map form (e.g., Fig. 1) when diagnosing current drought conditions. These variables were considered very helpful when used together because the current conditions could be evaluated with the ESI, whereas the RCI provides a longer view of how conditions have been changing in recent weeks. The probabilistic drought forecasts allowed the participants to anticipate which regions were most susceptible to drought development, which also influenced their opinion on current drought conditions. Each group was asked if these probabilistic forecasts would be useful during their decision-making process since they are not deterministic forecasts. Though some concerns were expressed regarding the potential for false alarms, the consensus was that these forecasts would be beneficial because most farmers and ranchers are accustomed to dealing with uncertainty when making decisions. Any tool that can provide reliable information is potentially useful.

Attendee feedback was more neutral when evaluating the ESI change anomalies because many people found them difficult to interpret, with the confusion primarily arising from the method used to compute the change anomalies. To more easily compare the magnitude of ESI changes occurring during different years and seasons, the change anomalies are not simple numerical differences between two weeks. Instead, they are standardized anomalies in which the observed difference in the ESI is normalized using a long-term climatology of ESI changes from 2000 to 2013. This conversion caused some confusion because, for example, a decrease in the ESI from -0.1
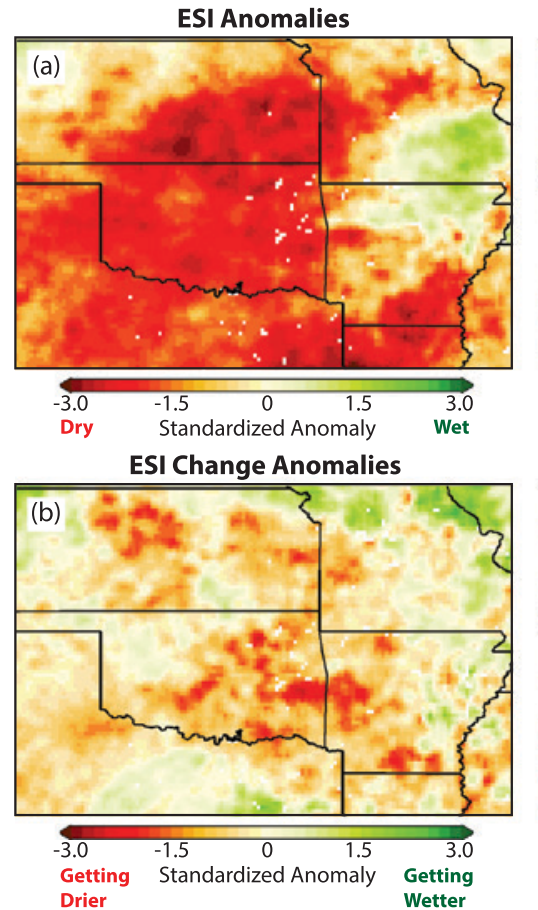

Rapid Change Index

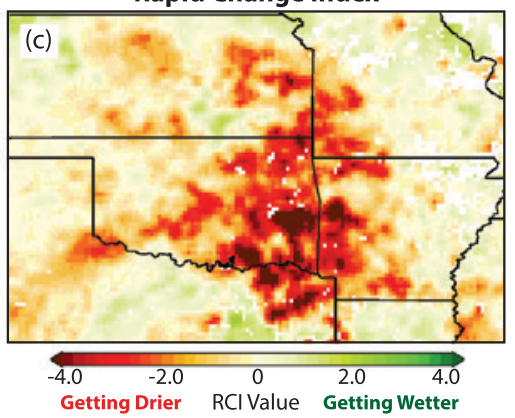

Chance of $>1$ Cat Increase over $\mathbf{2}$ Weeks

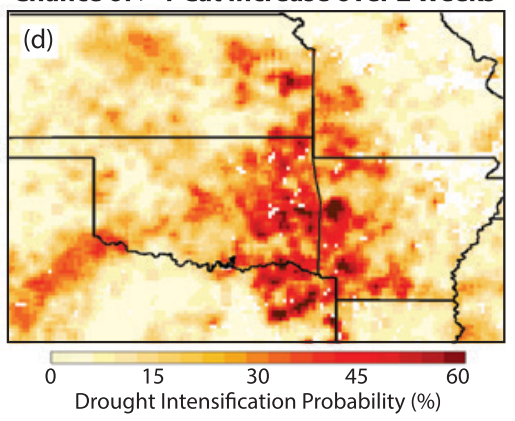

FIG. I. Domain images showing (a) ESI anomalies computed over a fourweek period, (b) standardized ESI change anomalies depicting changes in the ESI during the preceding week, (c) $\mathrm{RCI}$, and (d) the $\mathrm{RCl}$-derived probability of a one-category increase in the USDM drought severity occurring during the next two weeks. All images are valid on I Jul 201 I. 


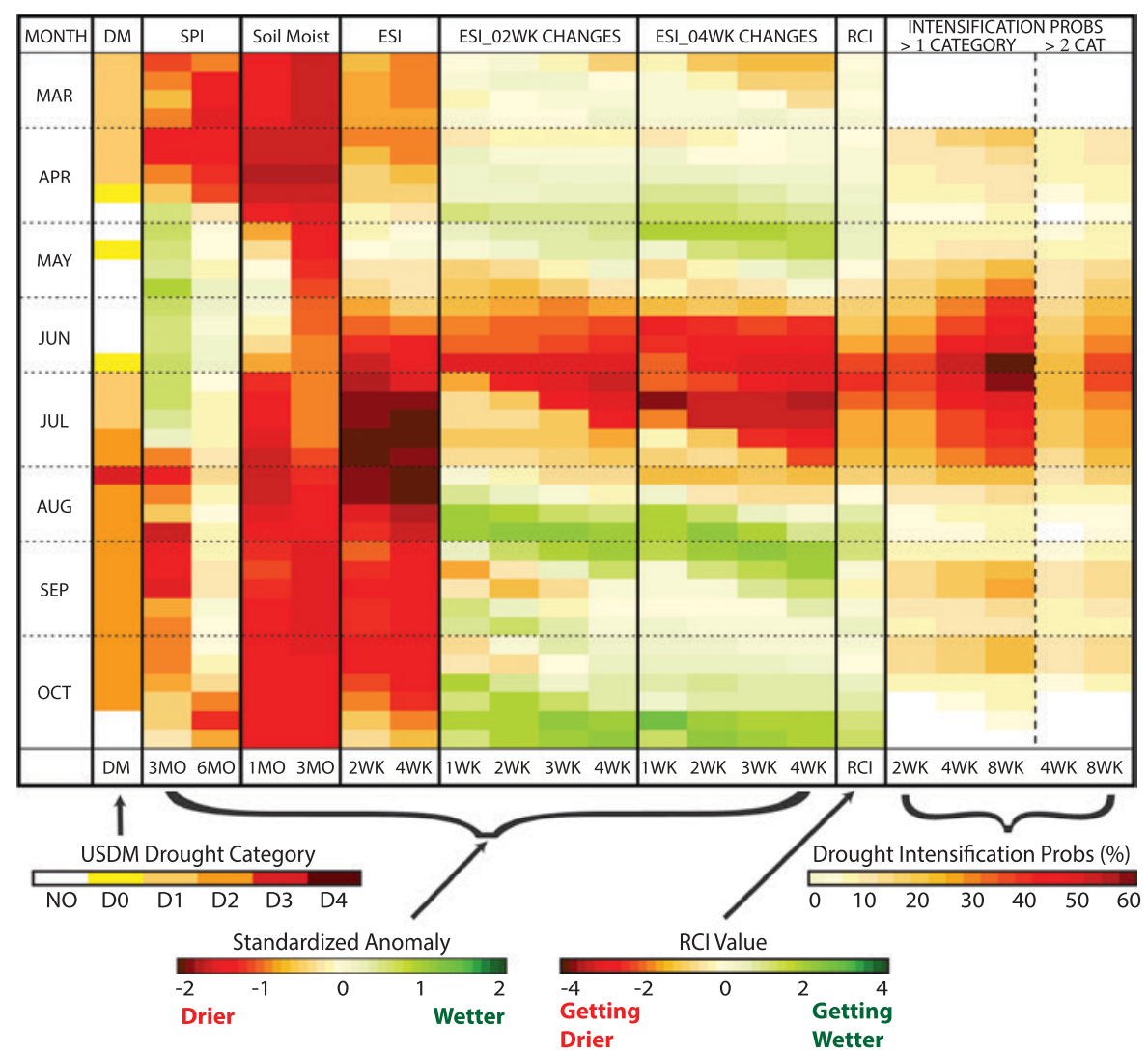

FIG. 2. Example "plume diagram" depicting the evolution of the 2012 flash drought event across eastern Oklahoma. The weekly USDM drought analysis is shown in column I. The Standardized Precipitation Index computed over 3- and 6-month periods is shown in columns 2 and 3, with total column soil moisture anomalies from the North American Land Data Assimilation system computed over I- and 3- month periods shown in columns 4 and 5 . ESI anomalies computed over 2- and 4-week periods are shown in columns 6 and 7. Standardized ESI change anomalies computed by differencing the 2- and 4-week ESI fields over I-, 2-, 3-, and 4-week time periods are shown in columns 8-15. The Rapid Change Index is shown in column 16, with various drought intensification probabilities computed from the RCI shown in columns I7-2I.

to -0.4 may be depicted as a standardized anomaly of -1.5 instead of the observed difference of -0.3 after this difference has been normalized. What the standardized change anomaly shows is that compared to climatology, the observed decrease in the ESI is unusually large and would be expected to occur only $7 \%$ of the time based on a normal distribution of changes. The attendees, however, generally preferred to use the RCI even though it is derived from these change anomalies, which indicates that the RCI adds value by transforming the change anomalies into a more easily understood format.

The attendees had a mixed reaction toward the plume diagrams (e.g., Fig. 2); however, several people commented that their opinion would likely improve after they gain more experience using them because the visualization method was unfamiliar to them and the images contain a lot of information that takes time to fully understand. Many of the attendees appreciated how the columns on the left (e.g., the ESI, SPI, and soil moisture anomalies) show the current conditions, whereas the columns on the right (e.g., the ESI change anomalies, RCI, and drought intensification probabilities) provide early warning of drought development. Together, these diagrams provide a concise view of both the current drought status and how things are changing with time. Overall, the attendee feedback regarding these diagrams was mostly negative at the first meeting, but was mostly positive at the second meeting, with $31 \%$ and $80 \%$ of the participants, respectively, expressing a positive opinion in the questionnaire. The higher percentage of positive responses at the second meeting was partially due to the presenters taking more time to explain all of the information included on these diagrams. After reading attendee comments from the first meeting, it was evident that additional time needed to be devoted to explaining these complex diagrams. The more positive comments at the second meeting suggest that the additional discussion time likely contributed to a higher perceived value by this group. Even so, several attendees commented that though this visualization tool has proven useful for researchers, it could be more difficult for nonscientists to use given its complexity unless it can be clearly explained through detailed examples. This dialogue 
illustrates the importance of directly engaging stakeholders when developing new tools.

POTENTIAL DROUGHT EARLY WARNING APPLICATIONS. Attendees at each meeting were asked to describe how access to drought early warning information would potentially affect their decisions. For ranchers, early warning of worsening conditions would allow them to preemptively move livestock to different pastures that are less susceptible to drought or to purchase supplemental feed. Several weeks advance notice of worsening conditions would be ideal for ranchers to make more informed decisions. Several people noted that forage management is more dynamic than farming because there are fewer adjustments a farmer can make after a crop is planted; thus, ranchers may realize larger benefits from improved drought early warning. Even so, farmers indicated that they would still benefit from early warning. For example, knowledge of an increased risk for drought development either locally or across other important farming areas may influence their marketing decisions. It may also help farmers determine if it would be beneficial to plant a cover crop after harvest and which one is most appropriate for the anticipated conditions.

Government agencies could potentially use drought early warning information to reposition resources such as equipment and personnel to better prepare for the adverse effects of drought across specific regions. It could also be used to assist ranchers through timely implementation of emergency haying programs. It was suggested that forecasts with a one or two month lead time would be ideal for these purposes. In addition, if drought indicators that are more sensitive to the initial stages of flash drought development, such as the ESI, are included as additional data layers when constructing the weekly USDM analyses, government program benefits and disaster declarations may also be affected. Many government programs and the timing of official disaster declarations are based on when the USDM reaches a certain intensity category (such as severe drought), and for how long it remains at or above that category. Thus, if the USDM reaches an important drought category earlier because it incorporates better drought early warning signals, this could lead to an earlier implementation of emergency farm programs and earlier drought declarations from state and federal agencies. This could be very beneficial to farmers and ranchers because it would promote earlier drought relief and mitigation efforts when flash drought events occur.
Other potential benefits due to improved drought early warning were also noted. For example, earlier warning of the potential for widespread severe drought conditions could help private insurance companies prepare for potentially higher insurance payouts by transferring funds to more liquid accounts and by hiring additional crop insurance claims adjustors and more efficiently deploying them across a region for field surveys. In addition, drought indices that depict moisture stress in vegetation are potentially useful when determining fire risk since they may provide a better measure of vegetation health than other drought indicators. From a state-level perspective, if drought early warning indices show that local vegetation is rapidly drying, managers may hesitate sending firefighting equipment and personnel to surrounding states because those resources may be needed within the state.

SUMMARY AND FUTURE WORK. This short note describes results from two focus group meetings that were held to present the ESI and associated datasets to stakeholders in two NIDIS pilot regions, and to better understand how they could use drought early warning information to prepare for flash drought development. Many attendees were excited about potential applications of the drought early warning tools and expressed a strong desire to optimize and refine these tools to match their specific needs and decision-making processes. These meetings facilitated interactions between researchers and stakeholders that provided valuable feedback that will improve the use of these datasets for drought mitigation efforts, and illustrate the importance of engaging stakeholders when developing new tools. Though U.S. agriculture was the primary focus of these meetings, drought early warning over subseasonal time scales should also be beneficial to other stakeholder groups.

Efforts are currently underway to transition the research version of the ESI to NOAA operations by mid-2015. The operational system will be used to compute the ESI with $10-\mathrm{km}$ resolution over most of North America and will improve data reliability and dissemination. Global implementation of the ESI, currently in prototype stage, may be an effective tool for early detection of food security flash points around the world. Feedback from the focus group meetings will be used to improve the visualization of these datasets and will guide efforts to provide the data in formats desired by end users. Additional focus group meetings may also be held with stakeholders in other parts of the 
United States to gain further insight when developing these tools. Continued development of drought early warning indicators that respond rapidly to changing conditions is necessary to reduce exposure to drought.

ACKNOWLEDGMENTS. We thank all of the focus group meeting attendees for their valuable contributions to this study and for informative discussions concerning the impact of flash droughts and potential uses of drought early warning information. This study was supported by the NOAA Climate Program Office's Sectoral Applications Research Program (SARP) under Grant NA13OAR4310122.

\section{FOR FURTHER READING}

Anderson, M. C., J. M. Norman, J. R. Mecikalski, J. A. Otkin, and W. P. Kustas, 2007a: A climatological study of evapotranspiration and moisture stress across the continental U.S. based on thermal remote sensing: 1. Model formulation. J. Geophys. Res., 112, D10117, doi:10.1029/2006JD007506.

$-, \ldots, \ldots, \ldots$, and $\_, 2007 \mathrm{~b}$ : A climatological study of evapotranspiration and moisture stress across the continental U.S. based on thermal remote sensing: 2. Surface moisture climatology. J. Geophys. Res., 112, D11112, doi:10.1029/2006JD007507.

Otkin, J. A., M. C. Anderson, C. Hain, I. Mladenova, J. Basara, and M. Svoboda, 2013: Examining flash drought development using the thermal infraredbased Evaporative Stress Index. J. Hydrometeor., 14, 1057-1074, doi:10.1175/JHM-D-12-0144.1.

$\ldots, \ldots, \ldots$, and M. Svoboda, 2014a: Examining the relationship between drought development and rapid changes in the Evaporative Stress Index. J. Hydrometeor., 15, 938-956, doi:10.1175/JHM-D-13-0110.1. ,,$-- \ldots$, and,$- 2014 \mathrm{~b}$ : Using temporal changes in drought indices to generate probabilistic drought intensification forecasts. J. Hydrometeor., 16, 88-105, doi:10.1175/JHM-D-14-0064.1.

\section{NEW! PRINT \& CD FORMATS}

"Professor Lackmann has prepared an excellent synthesis of quintessential modern midlatitude synoptic-dynamic meteorology."

- LANCE BOSART, Distinguished Professor, Department of Atmospheric and Environmental Sciences, The University of Albany, State University of New York

\section{Midlatitude Synoptic Meteorology:} Dynamics, Analysis, and Forecasting GARY LACKMANN

The past decade has been characterized by remarkable advances in meteorological observation, computing techniques, and datavisualization technology. Midlatitude Synoptic Meteorology links theoretical concepts to modern technology and facilitates the meaningful application of concepts, theories, and techniques using real data. As such, it both serves those planning careers in meteorological research and weather prediction and provides

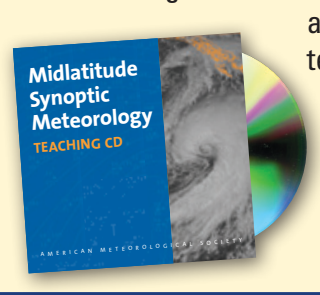
a template for the application of modern technology in the classroom.

Instructors: Midlatitude Synoptic Teaching CD, containing over 1,000 lecture slides, is now available!

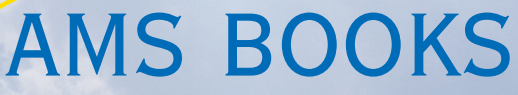

RESEARCH APPLICATIONS HISTORY www.ametsoc.org/amsbookstore 617-226-3998 